\title{
Dynamic balance performance of professional Turkish soccer players by playing position
}

\author{
Ates B.A. ${ }^{\mathrm{ABCDE}}$ \\ Faculty of Sport Science, Uşak University, Turkey
}

Authors' Contribution: A - Study design; B - Data collection; C - Statistical analysis; D - Manuscript Preparation; E - Funds Collection.

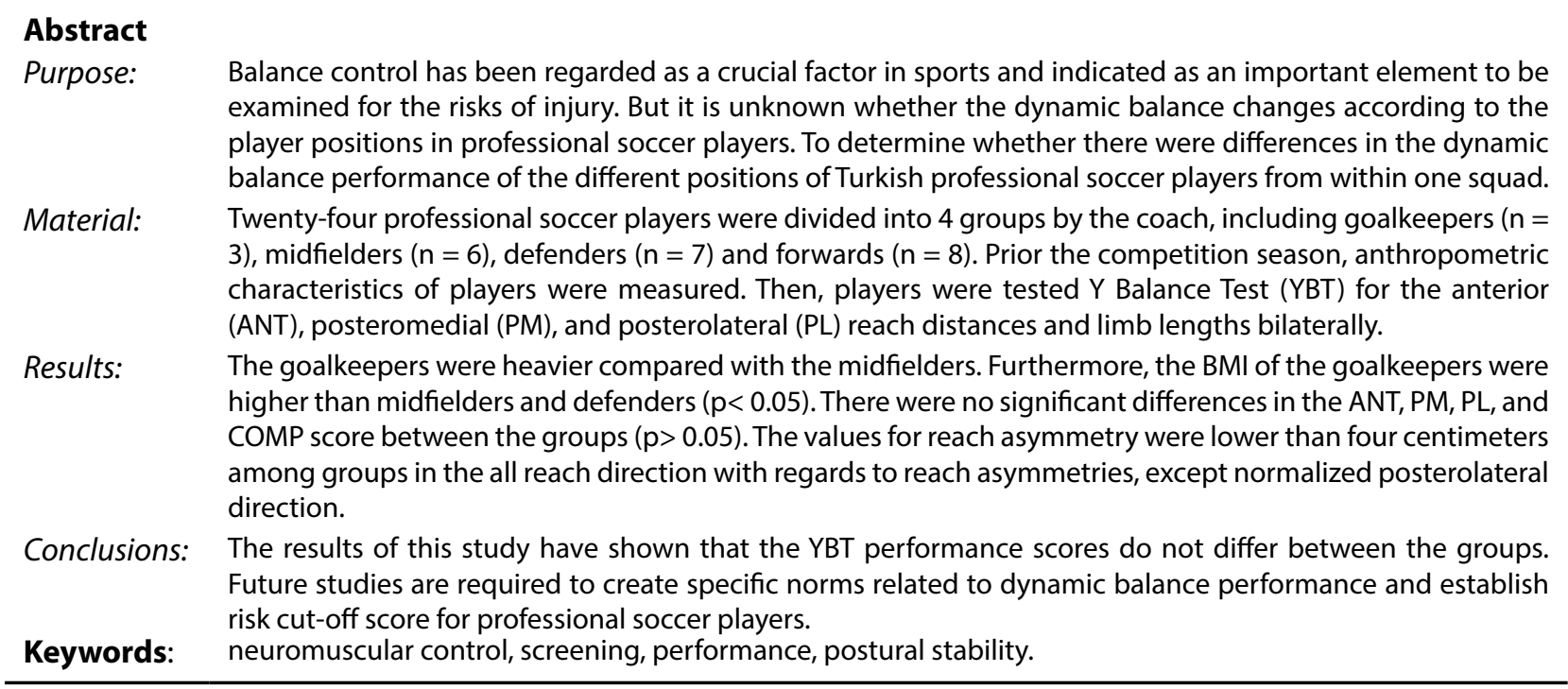

\section{Introduction}

Soccer is a high demand sporting activity which is commonly investigated [1,2] requires both technical and physical abilities as well as being high-intensity, intermittent sport [3]. It is also stated in most studies that it has risk of serious injury [1,4]. The most common injuries in soccer involve $87 \%$ of lower extremities with ankle sprains, thigh muscle strains and knee sprains have previously been suggested $[5,6]$ and it is known that $58 \%$ of these injuries are caused by non-contact mechanisms [5]. Some of the neuromuscular risk factors that cause lower extremity injuries indicated in young male soccer players include limb dominance (asymmetry) and reduced dynamic stability [7, 8]. Decreased dynamic stability is regarded as an intrinsic risk factor considered for injuries [9].

Balance control is regarded as a crucial factor in sports and considered an important component of motor skills. The dynamic balance, defined as the ability of the individual to maintain the stability of the center of mass during movement, is indicated as an important element to be examined for the risks of injury [1]. The importance of balance control for muscle damage and injuries, especially during high-intensity activities, is emphasized in most studies. Tropp et al. [10] have found that the number of ankle injuries with poor balance is almost four times higher than those with normal balance and Watson, [11] has also reported that Gaelic soccer players and athletes with poor balance (pitchers) similarly have ankle injuries,

(c) Ateş B.A., 2019

doi:10.15561/20755279.2019.0502 almost two times more. It has been suggested that using an injury screening tool assessing dynamic balance performance may be a useful in determining athletes with risk of injury [12]. The evaluation of dynamic balance ability and stability is applied regularly in soccer $[13,14]$ and it is emphasized that these assessments should include movements similar to the dynamic actions in soccer [15]. One of the most promising ones is considered as the evaluation of the dynamic balance using the $\mathrm{Y}$ Balance Test [9].

Soccer players are categorised into four different groups according to the playing positions, including goalkeepers, defenders, midfielders, and forwards. These players in various positions have the required anthropometric characteristics for different positionspecific physical performance and success [16]. It has been investigated whether these differences vary depending on player positions as well. Ostojic [18] has reported in the study conducted with professional Serbian players that the goalkeepers are most injured players during the season while those in other positions less likely to be injured. The high rate of injury in soccer players continues despite the scientific developments in the etiology of injuries, screening techniques and the determination of athletes who may be at greater risk [19]. Consequently, it is noted that the identification of athletes with muscle imbalance, decreased core stability and balance problems is important for preventing future injuries [20]. Additionally, Pau et al. [21] reports that the ability of balance in soccer players is a key factor in achieving optimum performance and reducing risk of injury. 
Previous studies have been conducted which aim to prevent injuries in female and male soccer players and evaluate dynamic balance through competing soccer and other branches [4, 2] and athletes in different levels [22]. However, it is unknown whether the dynamic balance changes according to the player positions in soccer. This study has hypothesized that dynamic balance ability is significantly different for each playing position in male professional soccer players. The purpose of this study, as a consequence, is to create specific norms related to dynamic balance, establish risk cut-off score for professional soccer players, help prevent future injuries through examining whether dynamic balance ability varies by the positions and provide useful information for coaches and athletes for post-injury trainings.

\section{Material and methods}

Subjects and Setting

24 male players of a second league professional soccer team (age: $24.3 \pm 5.25$ years) have voluntarily agreed to participate in the study. Athletes were divided into 4 groups by the coach, including goalkeepers $(\mathrm{n}=3)$, midfielders $(n=6)$, defenders $(n=7)$ and forwards $(n=8)$. Criteria for participation in the study has been determined as having no conditions preventing the completion of the balance test, no high-intensity exercise performed before the study and being the team's player. The research protocol was carried out in accordance with the Declaration of Helsinki and approved by the Uşak University Institutional Ethics Committee - 10/17.01.2019). The measurements were performed in July, two weeks before the competition season began. Athletes were performed familiarization season before the measurements for balance test. The athletes were clearly informed about the procedure to be applied and verbally encouraged to perform maximal performance during the measurements.

\section{Anthropometry}

Athletes' demographic characteristics including age, body, body weight and body fat percentage were collected prior the dynamic balance measurements. Athletes were asked to wear thin clothes without shoes during the measurements; body height was measured in centimeters using Mesitaş portable height gauge (Germany) and body weight was measured in kilograms using electronic weighing scale with $0.01 \mathrm{~kg}$ precision. Body Mass Index (BMI) was calculated using the formula BMI= weight/ height squared $\left(\mathrm{kg} / \mathrm{m}^{2}\right)$. The body fat percentage was calculated with skinfold thickness measurement using a Harpenden Skinfold Caliper. Skinfold measurements were taken on 10 sites as indicated by Parizkova [23].

Dynamic Balance Ability Test

The "Y Balance Test" protocol was used to measure dynamic balance ability. The length of each participant's leg was recorded in centimeters in the supine position, measured from the anterior superior iliac spine to the distal portion of the medial malleolus. The dominant (kicking) limb was determined according to self-reported of the athletes [14]. The measurements were performed barefoot, on a hard surface in 3 directions and Anterior (ANT) was tested from the toe aligned to the origin while Posteromedial (PL) and Posteriolateral (PM) were based on the distance between heel and furthest possible point to reach. Participants were asked to perform fingertip light touch with their reach foot as keeping their hands on the iliac and heels on the ground during the trial. A short demonstration was performed by the experienced researcher on implementation of the test before measurement and the best 3 reaches were recorded in all directions after the participants were allowed to try at least 4 times [24]. Each participant was given a 2-minute resting time and then they were asked to perform 3 reaches in each direction after the completion of the test. It was considered as a failed attempt to transfer the body weight through the reach foot, ground the heel of the stance foot or remove hands from the hips and the measurement was repeated after the participant was orally informed. All reach distances were recorded in centimeters. After the data were collected, obtained scores were normalized using the formula: "Maximal Reach Distance/Limb Length) x $100=$ Largest Reach Distance \%" for each direction in order to eliminate the advantage of the limb length [24]. The total score (COMP) was calculated by averaging the normalized ANT, PL and PM scores. The average of the three recorded trials and COMP score have been used for analysis to ensure a reliable measurement of the dynamic balance [24].

Statistical Analysis

The SPSS 23 software package program was used for all data analysis. Nonparametric testing was preferred in statistical analysis due to lack of sample size. KruskalWallis H Test was performed to determine whether there was a difference between the groups according to the normalized YBT reach distances based on the positions. The data were presented as median and interquartile range due to the use of nonparametric testing [25]. Significance level was set as $\mathrm{p}<0.05$.

\section{Results}

The descriptive characteristics of soccer players by playing position are shown in Table 1 . There was a significant difference between groups only in the body weight and BMI. The goalkeepers were heavier compared with the midfielders $(p<0.05)$. Furthermore, the BMI of the goalkeepers were higher than midfielders and defenders $(\mathrm{p}<0.05)$.

The parameters of the YBT performance are presented in Table 2. There were no significant differences in the ANT, PM, PL, and COMP score between the groups ( $p$ $>0.05$ ). The values for reach asymmetry were lower than four centimeters among groups in the all reach direction with regards to reach asymmetries, except normalized posterolateral direction. The goalkeepers and defenders have a difference greater than four centimeters in the normalized posterolateral reach direction between the legs, 4.09 and 5.93, respectively (Table 2). 
Table 1. Age, body height, body mass, BMI, BF, leg length, and training age an of soccer players by position. Data reported as median and interquartile ranges $(n=24)$.

\begin{tabular}{llllll}
\hline Parameters & All $\mathbf{( n = 2 4 )}$ & $\begin{array}{l}\text { Goalkeepers } \\
(\mathbf{n = 3}\end{array}$ & $\begin{array}{l}\text { Midfielders } \\
(\mathbf{n}=\mathbf{6})\end{array}$ & $\begin{array}{l}\text { Defenders } \\
(\mathbf{n}=\mathbf{7})\end{array}$ & $\begin{array}{l}\text { Forwards } \\
(\mathbf{n}=\mathbf{8})\end{array}$ \\
\hline Age (years) & $24.3(5.25)$ & $23.3(0)$ & $22.7(3)$ & $25.1(5)$ & $25(9.75)$ \\
Body Height (cm) & $1.82(0.02)$ & $1.87(0)$ & $1.80(0.05)$ & $1.84(0.11)$ & $1.79(0.04)$ \\
Body Weight (kg) & $75.7(12.2)$ & $83.9(0)^{*}$ & $72.5(4.73)$ & $76.5(12.9)$ & $74.2(13.8)$ \\
BMI (kg/m²) & $22.9(1.97)$ & $24.1(0)^{*}$ & $22.3(1.33)$ & $22.5(1.2)$ & $23.2(4.45)$ \\
BF (\%) & $12.1(2.28)$ & $13.1(0)$ & $11.6(1.7)$ & $12.1(2.4)$ & $12.1(2.95)$ \\
Leg Length (cm) & $94.8(5.75)$ & $96.3(0)$ & $93.7(4.5)$ & $96.9(13)$ & $93.1(7.75)$ \\
Training Age (year) & $13.7(5.75)$ & $13.7(0)$ & $12.2(6.75)$ & $15(3)$ & $13.8(14)$ \\
\hline
\end{tabular}

Abbreviation: BMI: Body Mass Index; BF: Body Fat Percentage; * Significant difference in relation to midfielders ( $<$ $0.05) ; *$ Significant difference in relation to midfielders and defenders $(p<0.05)$.

Table 2. Normalised reach distances (\%) and reach asymmetries of soccer players by position. Data reported as median and interquartile ranges $(n=24)$.

\begin{tabular}{|c|c|c|c|c|c|}
\hline Parameters & All $(n=24)$ & $\begin{array}{l}\text { Goalkeepers } \\
(n=3)\end{array}$ & $\begin{array}{l}\text { Midfielders } \\
(n=6)\end{array}$ & $\begin{array}{l}\text { Defenders } \\
(n=7)\end{array}$ & $\begin{array}{l}\text { Forwards } \\
(n=8)\end{array}$ \\
\hline \multicolumn{6}{|l|}{ Anterior (\%) } \\
\hline Dominant Leg & $68.1(8.68)$ & $69.6(0.00)$ & $66.6(10.66)$ & $64.1(13.72)$ & $72.2(18.38)$ \\
\hline Nondominant Leg & $67.8(9.00)$ & $69.7(0.00)$ & $63.8(14.14)$ & 67.5 (13.39) & 70.4 (13.51) \\
\hline Reach Asymmetry & $0.28(7.05)$ & $0.11(0.00)$ & 2.77 (9.85) & 3.46 (3.22) & $1.82(5.40)$ \\
\hline \multicolumn{6}{|l|}{ Posteromedial (\%) } \\
\hline Dominant Leg & $117.1(11.40)$ & $118.2(0.00)$ & $116.7(9.80)$ & $113.6(24.02)$ & $120.1(12.34)$ \\
\hline Nondominant Leg & $116.1(12.21)$ & $118.2(0.00)$ & 115 (11.95) & $112.8(26.38)$ & $119(20.18)$ \\
\hline Reach Asymmetry & $1.05(5.06)$ & $0.001(0.00)$ & $1.68(4.72)$ & $0.86(4.18)$ & $1.14(5.72)$ \\
\hline \multicolumn{6}{|l|}{ Posteriolateral (\%) } \\
\hline Dominant Leg & $115.5(11.18)$ & $117.7(0.00)$ & 111.5 (9.13) & $103.1(16.84)$ & $116.6(20.04)$ \\
\hline Nondominant Leg & $112.9(12.31)$ & $113.6(0.00)$ & 110.9 (15.38) & $109.1(18.45)$ & $117.6(18.74)$ \\
\hline Reach Asymmetry & $1.37(7.04)$ & $4.09(0.00)$ & $0.67(5.02)$ & $5.93(11.28)$ & $0.95(6.25)$ \\
\hline \multicolumn{6}{|l|}{ Composite (\%) } \\
\hline Dominant Leg & 98.9 (7.28) & $101.8(0.00)$ & 98.3 (9.39) & $93.6(17.34)$ & 103 (14.36) \\
\hline Nondominant Leg & $98.9(10.31)$ & $100.5(0.00)$ & 96.6 (12.47) & $96.5(20.65)$ & $102.3(16.28)$ \\
\hline Reach Asymmetry & $0.01(4.20)$ & $1.32(0.00)$ & $1.71(4.46)$ & $2.84(3.30)$ & $0.67(3.06)$ \\
\hline
\end{tabular}

\section{Discussion}

The aim of this study is to examine the dynamic balance performances of a second league professional male soccer team and determine whether this dynamic balance ability varies by playing positions of the athletes. Contrary to our hypothesis, the results of the study have identified no differences in normalized dynamic balance performance by playing position among professional soccer players. Additionally, asymmetry was present only in the posterolateral direction among goalkeepers and midfielders.

The study demonstrates that there are no differences in normalized reach distances of all YBT scores among goalkeepers, midfielders, defenders, and forwards in the dominant and nondominant limb. It is known that athletes need specific physical activities and requirements as a result of playing in a special position in soccer and repeated trainings and there are studies indicating that numerous physical performances of the players as aerobic and anaerobic performance, agility, sprint ability and muscle strength vary by their position $[16,26]$. However, to the author's knowledge, no studies were found in the literature evaluating dynamic balance abilities according to the playing positions. There are only two studies focusing on the positions. Pau et al. [21] examined static balance abilities in elite soccer players by playing position and Bizid and Paillard [13] examined the effects of position on postural control in offensive and defensive players of the national team. In addition, another study examining the effects of playing position (forwards/ backs) on dynamic balance performance was conducted by Jonstan et al. [27] among elite male Rugby players (under-20 and senior players) and they indicated that backs reached the longest distance in both age groups.

Postural control and balance abilities are built on a complex system that contributes to postural control, including visual, somatosensor and vestibular systems and there are studies which state that it is affected by various 
anthropometric variables [18, 28]. Ozunlu et al. [29] and Jonhston et al. [27] have indicated that increased body mass reduces the dynamic balance performance measured using Star Excursion Balance Test (SEBT) and YBT; Gribble et al. [30] have indicated that there is a significant relationship between the height and 6 of 8 SEBT directions; Tabrizi et al. [31] have reported that there is a significant relationship between the dynamic balance performance measured using YBT and body fat percentage, BMI and weight among handball, basketball, futsal and volleyball players aged between 20 and 30. There are studies that similarly analyze differences between age groups according to postural control $[32,33]$. In the current study, a statistically higher value was obtained for weight and BMI in goalkeepers compared to midfielders and for BMI compared to defensive players. No significant difference was found in terms of age, weight, height, BMI, BF and limb length between groups according to the positions. The findings obtained in this study are inconsistent with the results of previous studies showing anthropometric differences according to the positions of professional footballers. It is considered in this study that there is no difference in the dynamic balance between the groups due to the lack of anthropometric differences.

Another finding also achieved in the current study is that reach asymmetry values are four centimeters higher than normalized posterolateral reach direction only among the goalkeepers and defensive players. All values are less than four centimeters in other directions and groups. This seems to be the most demanding among all three directions and may create a potential risk factor for lower extremity injury with regard to the destabilizing moment [34]. Plisky et al. [12] have indicated that the players with an anterior right/left reach range greater than $4 \mathrm{~cm}$ are 2,5 times more likely to have lower extremity injuries.

The primary hypothesis of this study is that the dynamic balance performance varies by position due to the requirement for specific physical activities and other necessities of the players as a result of different positions and repeated trainings. In addition, the study aimed to provide reference values for dynamic balance performances according to their positions. No such studies providing reference values for the YBT for professional soccer players based on their positions have been found in the literature. In this respect, future studies conducted with more participants and evaluation of YBT according to the positions are essential for clinicians and researchers to obtain normative values.

The limitations of the study should also be noted. The sample group of the study was relatively small $(n=24)$ and the measurements of the professional players of a single team were taken. Adding more participants will increase the external validity of this research. Additionally, the number of athletes in the compared positions were not equal. It can be concluded that these outcomes affect the results of the statistics. However, recent studies indicate that the data obtained among individuals may still be informative despite demonstration of a specific team and absence of equal distribution according to the player positions [26].

\section{Conclusion}

In conclusion, the results of this study have shown that no difference was found based on the position-related performance among players on the YBT score. Future studies are required to create specific norms related to dynamic balance performance and establish risk cutoff score for professional soccer players. Additionally, they should analyze the relationship between dynamic balance and value parameters such as lower body strength and range of motion (ROM). Furthermore, the reach asymmetry values less than four centimeters are acceptable conclusions for all positions in such cases as practical applications for the conditioning athletes to benefit from, values obtained in a position, prevention of injuries, pre-season screening and athlete selection.

\section{Acknowledgements}

The author would like to thank the players and technical team for their contribution.

\section{Funding}

No specific funding was received for this study.

\section{Conflict of interest}

There were no conflicts of interest. 


\section{References}

1. Butler RJ, Southers C, Gorman PP, Kiesel KB, Plisky PJ. Differences in soccer players' dynamic balance across levels of competition.JournalofAthletic Training, 2012;47(6):616-620. https://doi.org/10.4085/1062-6050-47.5.14

2. Gerbino PG, Griffin ED, Zurakowski D. Comparison of standing balance between female collegiate dancers and soccer players. Gait Posture, 2007; 26 (4): 501- 507. https://doi.org/10.1016/j.gaitpost.2006.11.205

3. Steindl R, Kunz K, Schrott-Fischer A, Scholtz AW. Effect of age and sex on maturation of sensory systems and balance control. Developmental Medicine and Child Neurology, 2006; 48: 477-482. https://doi.org/10.1017/S0012162206001022

4. Bressel E, Yonker JC, Kras J, Heath EM. Comparison of static and dynamic balance in female collegiate soccer, basketball, and gymnastics athletes. Journal of Athletic Training. 2007; 42 (1): 42-46.

5. Agel J, Evans TA, Dick R, Putukian M, Marshall SW. Descriptive epidemiology of collegiate men's soccer injuries: National Collegiate Athletic Association Injury Surveillance System, 1988-1989 through 2002-2003. Journal of Athletic Training, 2007; 42 (4): 270-277.

6. Kiani A, Hellquist E, Ahlqvist K, Gedeborg R, Michaelsson K, BybergL.Prevention of soccer-relatedkneeinjuriesinteenaged girls. Archives of Internal Medicine, 2010; 170 (1): 43- 49. https://doi.org/10.1001/archinternmed.2009.289

7. Read PJ, Oliver JL, De Ste Croix MBA, Myer GD, Lloyd RS. Assessment of injury risk factors in male youth soccer players. The Journal of Strength and Conditioning Research, 2016; 38 (1): 12-21. https://doi.org/10.1519/SSC.0000000000000184

8. Read PJ, Oliver JL, Croix MBDS, Myer GD, Lloyd RS. Neuromuscular risk factors for knee and ankle ligament injuries in male youth soccer players. Sports Medicine, 2016; 46(8): 1059-1066. https://doi.org/10.1007/s40279-016-0479-z

9. Gonell AC, Romero JAP, Soler LM. Relationship between the $\mathrm{Y}$ balance test scores and soft tissue injury incidence in a soccer team. International Journal of Sports Physical Therapy, 2015; 10 (7): 955-966.

10.Tropp H, Ekstrand J, Gillquist J. Stabilometry in functional instability of the ankle and its value in predicting injury. MedicineandScienceinSportsAndExercise, 1984;16(1):64-6. https://doi.org/10.1249/00005768-198401000-00013

11.Watson AWS. Ankle sprains in players of the field-games Gaelic football and hurling. The Journal of Sports Medicine and Physical Fitness, 1999; 39 (81): 66-70.

12.Plisky PJ, Rauh MJ, Kaminski TW, Underwood FB. Star Excursion Balance Test as a predictor of lower extremity injury in high school basketball players. The Journal of Orthopedic and Sports Physical Therapy, 2006; 36 (12): 911-919. https://doi.org/10.2519/jospt.2006.2244

13.Bizid R, Paillard T. Do the soccer players' postural activities at national level of competition differ between offensive and defensive players? Science and Sport. 2006; 21: 23- 25. https://doi.org/10.1016/j.scispo.2005.12.003

14.Onofrei R-R, Amaricai E, Petroman R, Surducan D, Suciu O. Preseason Dynamic Balance Performance in Healthy Elite Male Soccer Players. American Journal of Men's Health, 2019;13:155798831983192. https://doi.org/10.1177/1557988319831920

15.Read PJ, Oliver JL, Croix MBDS, Myer GD, Lloyd RS. A review of field-based assessments of neuromuscular control and their utility in male youth soccer players. The Journal of
Strength and Conditioning Research, 2009; 33 (1): 283-299. https://doi.org/10.1519/JSC.0000000000002069

16.Kubayi A, Paul Y, Mahlangu P, Toriola A. Physical Performance and Anthropometric Characteristics of Male South African University Soccer Players. Journal of Human Kinetics. 2017; 60 (1): 153- 158. https://doi.org/10.1515/hukin-2017-0098

17.Ostojic S. M. Comparing sports injuries in soccer: Influence of a positional role. Research in Sports Medicine, 2003; 11 (3): 203-208. https://doi.org/10.1080/15438620390231229

18.Hirabayashi S, Iwasaki Y. Developmental perspective of sensory organisation on postural control. Brain and Development, 1995; 17: 111- 113. https://doi.org/10.1016/0387-7604(95)00009-Z

19.Grooms DR, Palmer T, Onate JA, Myer GD, Grindstaff T. Soccer-specific warm-up and lower extremity injury rates in collegiate male soccer players. Journal of Athletic Training, 2013; 48(6): 782- 789. https://doi.org/10.4085/1062-6050-48.4.08

20.Engquist KD, Smith C. A, Chimera NJ, Warren M. Performance comparison of student-athletes and general college students on the functional movement screen and the Y balance test. The Journal of Strength and Conditioning Research. 2015; 29 (8): 2296- 2303. https://doi.org/10.1519/JSC.0000000000000906

21.Pau M, Ibba G, Leban B, Scorcu M. Characterization of static balance abilities in elite soccer players by playing position and age. Research in Sports Medicine, 2014; 22 (4): 355-367. https://doi.org/10.1080/15438627.2014.944302

22.Paillard T, Noe F, Riviere T, Marion V, Montoya R, Dupui P. Postural performance and strategy in the unipedal stance of soccerplayers at different levels of competition. Journal of Athletic Training, 2006; 41 (2): 172-176.

23.Parizkova S. Body fat and physical fitness. The Hague, The Netherlands. Martinus Nijhoff BV; 2012.

24.Gribble PA, Hertel J, Plisky P. Using the star excursion balance test to assess dynamic postural-control deficits and outcomes in lower extremity injury: A literature and systematic review. Journal of Athletic Training, 2012; 47 (3): 339- 357. https://doi.org/10.4085/1062-6050-47.3.08

25.Scott BR., Lockie RG, Davies SJ, Clark AC, Lynch DM, Janse de Jong, X.AK. The physical demands of professional soccer players during in-season field-based training and match-play. Journal of Australian Strength and Conditioning, 2014; 22(4): 48-52.

26.Lockie RG, Moreno MR, Lazar A, Orjalo AJ, Giuliano DV, Risso FG, Jalilvand F. The physical and athletic performance characteristics of Division I collegiate female soccer players by position. The Journal of Strength and Conditioning Research. 2018; 32 (2): 334-343. https://doi.org/10.1519/JSC.0000000000001561

27.Johnston W, Duignan C, Coughlan GF, Caulfield B. Dynamic balance performance varies by position but not by age group in elite Rugby Union players-a normative study. Journal of Sports Science, 2019; 37 (11): 1308- 1311. https://doi.org/10.1080/02640414.2018.1557360

28.Butz SM, Sweeney JK, Roberts PL, Rauh MJ. Relationships among age, gender, anthropometric characteristics, and dynamic balance in children 5 to 12 years old. Pediatric Physical Therapy, 2015; 27 (2): 126- 133. https://doi.org/10.1097/PEP.0000000000000128

29.Ozunlu N, Basari GO, Baltaci G. The effects of carrying extra weight on ankle stability in adolescent basketball players. The Foot, 2010; 20 (2): 55-60. 
https://doi.org/10.1016/j.foot.2010.03.006

30. Gribble PA, Hertel J. Considerations for normalizing measures of the Star Excursion Balance Test. Measurement in Physical Education and Exercise Science, 2003; 7 (2): 89- 100. https://doi.org/10.1207/S15327841MPEE0702_3

31.Tabrizi HB, Abbasi A, Sarvestani HJ. Comparing the static and dynamic balances and their relationship with the anthropometrical characteristics in the athletes of selected sports. Middle-East Journal of Scientific Research, 2013; 15 (2): 216-221.

32.Arela JA, Jeka JJ, Clark JE. Postural control in children. Coupling to dynamic somatosensory information. Experimental Brain Research, 2003; 150: 434- 442. https://doi.org/10.1007/s00221-003-1441-5
33.Forssberg H, Nashner LM. Ontogenetic development of postural control in man: Adaptation to altered support and visual conditions during stance. Journal of Neuroscience, 1982; 2: 545- 552. https://doi.org/10.1523/JNEUROSCI.02-05-00545.1982

34.Gkrilias P, Zavvos A, Fousekis K, Billis E, Matzaroglou C, Tsepis E. Dynamic balance asymmetries in pre-season injuryprevention screening in healthy young soccer players using the Modified Star Excursion Balance Test - a pilot study. Journal of Physical Therapy Science, 2018;30(9): 1141-1144. https://doi.org/10.1589/jpts.30.1141

\section{Information about the author:}

Ateş B.A.; http://orcid.org/0000-0002-6339-3564; atesbhr@gmail.com; Faculty of Sport Science, Uşak University; Ankara İzmir Yolu 8.Km Bir Eylül Kampüsü, Merkez / UŞAK, Turkey.

\section{Cite this article as:}

Ateş BA. Dynamic balance performance of professional turkish soccer players by playing position. Physical education of students, 2019;23(5):223-228.

https://doi.org/10.15561/20755279.2019.0502

This is an Open Access article distributed under the terms of the Creative Commons Attribution License, which permits unrestricted use, distribution, and reproduction in any medium, provided the original work is properly cited http://creativecommons.org/licenses/by/4.0/deed.en

Received: 28.06.2019

Accepted: 03.08.2019; Published: 26.10.2019 